\title{
Self-Determination Skills
}

and Opportunities of

Transition-Age Youth With

Emotional Disturbance

and Learning Disabilities

ERIK W. CARTER

University of Wisconsin-Madison

\section{KATHLEEN L. LANE}

Peabody College of Vanderbilt University

MELINDA R. PIERSON

California State University-Fullerton

GARBARA GLAESER

California State University-Fullerton

ABSTRACT: This study examined the self-determination of adolescents with emotional disturbance (ED) and learning disabilities (LD) from the perspectives of special educators, parents, and the students themselves. Differences in self-determination ratings were associated with both disability group and respondent. Specifically, adolescents with ED were found to have lower ratings of selfdetermination than students with $L D$, with the most pronounced differences evident from the teacher perspective. Furthermore, students with ED identified infrequent opportunities at school and home for engaging in self-determined behavior, whereas educators and parents differed in their assessments of opportunities in each setting. Implications regarding increasing the self-determination skills and opportunities of adolescents with disabilities are discussed.

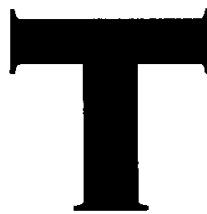

he importance of promoting selfdetermination among adolescents with disabilities has been highlighted in recent legislative, policy, and funding initiatives (Individuals with Disabilities Education Improvement Act, 2004; National Council on Disability,
2004; President's Commission on Excellence in Special Education, 2002; Rehabilitation Act Amendments of 1992 and 1998) and garnered substantial attention in the published literature (e.g., Algozzine, Browder, Karvonen, Test, \& Wood, 2001; Malian \& Nevin, 2002). Moreover, research is accruing steadily that suggests that 
enhanced self-determination may play a role in improving student outcomes, including academic performance (Martin et al., 2003), employment status (Wehmeyer \& Palmer, 2003), postsecondary participation (Field, Sarver, \& Shaw, 2003), independence (Sowers \& Powers, 1995), and quality of life (Wehmeyer \& Schwartz, 1997). As a result, promoting students' self-determination now constitutes an important component of best practices in the education of transition-age youth with disabilities (e.g., Council for Exceptional Children, 2003; Field \& Hoffman, 2002; Field, Martin, Miller, Ward, \& Wehmeyer, 1998).

Successful postschool transitions require that adolescents assume more prominent roles in educational and life planning-understanding and communicating their strengths and needs, setting and working toward self-selected goals, advocating for themselves, and self-assessing their own progress and outcomes. Such actions characterize people who are self-determined and are presumed to improve adolescents' prospects for achieving personally meaningful outcomes (Field et al., 1998). Despite considerable efforts directed toward understanding and increasing the self-determination of adolescents with intellectual disabilities and learning disabilities, far less is known about the self-determination of high school students with emotional disturbance (ED). To illustrate, recent research reviews indicated that youth with ED represented less than $2 \%$ of participants in studies examining the impact of student involvement in educational planning (Test et al., 2004) and less than $4 \%$ of participants in studies evaluating the effectiveness of interventions aimed at promoting self-determination (Algozzine et al., 2001). Additional research is needed to address several gaps associated with the literature concerning the self-determination of students with ED.

Descriptive data addressing the skills, knowledge, and perceptions of students with ED in the area of self-determination would assist researchers and practitioners in (a) identifying specific areas of strength and need, (b) developing instructional objectives and curricular materials, and (c) designing effective intervention efforts to increase self-determined behavior. The in- and postschool outcomes of adolescents with ED-outcomes that generally are worse than for any other disability category-serve as indicators that students may exhibit substantial skill deficits in the area of self-determination (e.g., Wagner, Cameto, \& Newman, 2003; Wood \& Cronin, 1999). However, clear descriptive data addressing the selfdetermination of adolescents with ED remain absent from the literature. Few peer-reviewed studies have assessed the self-determination of high school students with ED and, of those that have included participants with ED, it is not possible to extract the ratings of these students from the larger sample (e.g., Houchins, 2002).

Research on the self-determination of adolescents with ED would be strengthened when accompanied by comparisons to youth receiving special education services under other disability categories, particularly students with learning disabilities (LD). In many schools, students with ED and LD may be served by the same teachers and/or in similar classroom settings (Carlson, Brauen, Klein, Schroll, \& Westat, 2002; Sabornie $\&$ deBettencourt, 2004). Such comparisons would provide information regarding whether

\section{. . clear descriptive data addressing the self-determination of adolescents with $E D$ remain absent from the literature.}

students with ED and LD share similar instructional needs in the area of self-determination and, if so, could inform decisions about whether similar intervention packages may be warranted. Because disability labels are associated with differences in adolescents' academic, social, and behavioral skills (e.g., Anderson, Kutash, \& Duchnowski, 2001; Lane, Carter, Pierson, \& Glaeser, in press), it is plausible that similar differences exist in the area of self-determination. In fact, possible differences in self-determination skills among students may mediate some of the other discrepancies in the academic, social, and behavioral skills evident among students with ED and LD.

In addition to understanding the extent to which students possess self-determination skills in their behavioral repertoires, it also is essential to evaluate the extent to which opportunities exist 
for students with disabilities to utilize and refine those skills (Grigal, Neubert, Moon, \& Graham, 2003). School and home environments may either foster or inhibit the acquisition and maintenance of students' self-determined behavior (Ryan \& Deci, 2000). Students' capacity for self-determination and their opportunities to engage in self-determined behavior likely interact, synergistically impacting students' development of selfdetermination. For example, self-determined adolescents may seek out, create, and/or be extended frequent opportunities to engage in selfdetermined behaviors (e.g., choice making, decision making, problem-solving, goal setting, self-advocacy), while these opportunities, in turn, provide the context within which students can further refine their self-determined behaviors (Mithaug, Mithaug, Agran, Martin, \& Wehmeyer, 2003). In contrast, students who have-or are perceived by others to have-limited skills related to self-determination, subsequently may be extended fewer opportunities by educators and parents to utilize and further develop their skills. Previous refereed studies have not examined both the skills and opportunities related to self-determined behavior for youth with disabilities. However, prior survey research suggests that opportunities for students to engage in self-determined behavior may be limited in typical secondary schools (Agran, Snow, \& Swaner, 1999; Wehmeyer, Agran, \& Hughes, 2000).

Because self-determination is a multidimensional construct, research is needed that examines students' self-determination from multiple perspectives. The perspectives of educators and parents may be particularly salient, as these persons have substantial, yet unique, occasions from which to observe students' opportunities for selfdetermination and to evaluate the extent to which students engage successfully in self-determined behaviors. Although parents' perceptions of their children's opportunities for self-determination at school have been explored (Grigal et al., 2003; Zhang, Katsiyannis, \& Zhang, 2002), little is known about their assessments of opportunities at home or the extent to which their children actually engage in self-determined behavior beyond the school day. Such assessments are important given the prominent role parents potentially play in nurturing or hindering self-determined behav- ior (Karvonen, Test, Wood, Browder, \& Algozzine, 2004). Similarly, although teachers have been queried about the extent to which they promote self-determination for youth with disabilities in general (Wehmeyer et al., 2000; Zhang, Wehmeyer, \& Chen, 2005), less is known about their evaluations of students' actual abilities, knowledge, and perceptions related to self-determination, particularly for adolescents with ED. Finally, only one study has examined the evaluations of adolescents with ED (i.e., adjudicated youth) concerning their own self-determination skills (Houchins, 2002), and none have queried these students regarding their opportunities to engage in self-determined behavior in school and home settings. Research directly comparing the evaluations of students with those of their parents and teachers would yield important information regarding whether stakeholders share similar or divergent perceptions of skills and opportunities that promote self-determined behavior.

In the present study, we examined the capacities and opportunities to engage in self-determined behavior of adolescents with emotional disturbance. Specifically, we sought to answer four questions. First, what are the self-determination prospects of adolescents with ED? Second, how do students with ED and LD compare with regard to their capacity for and opportunities to engage in self-determined behavior? Third, to what extent do educators, parents, and students share similar or divergent views of adolescents' capacities and opportunities in the area of self-determination? Fourth, what is the relation between students' capacities to engage in self-determined behavior and the opportunities available to them at school and home?

\section{METHOD}

\section{PARTICIPANTS}

The self-determination of 85 high school students with $\mathrm{ED}(n=39)$ or $\mathrm{LD}(n=46)$ was assessed by special educators, parents, and the students.

Students With Disabilities. Students ranged in age from 14.1 to 19.2 years ( $M=16.2$ years), with the majority being male $(64.7 \%)$. Thirtyeight students were Caucasian $(44.7 \%), 30$ were Hispanic (35.3\%), 9 were African American 


\begin{tabular}{|c|c|c|c|c|}
\hline & \multicolumn{2}{|c|}{$\begin{array}{c}\text { Students With } \\
\text { Emotional Disturbance }\end{array}$} & \multicolumn{2}{|c|}{$\begin{array}{c}\text { Students With } \\
\text { Learning Disabilities }\end{array}$} \\
\hline & Frequency (\%) & $M(S D)$ & Frequency (\%) & $\mathrm{M}(\mathrm{SD})$ \\
\hline$N$ & 39 & & 46 & \\
\hline Age & & $16.16(1.31)$ & & $16.21(1.27)$ \\
\hline \multicolumn{5}{|l|}{ Ethnicity } \\
\hline $\begin{array}{l}\text { Caucasian } \\
\text { Hispanic } \\
\text { African American } \\
\text { Asian American } \\
\text { Other ethnicities }\end{array}$ & $\begin{array}{rr}19 & (48.7) \\
13 & (33.3) \\
3 & (7.7) \\
2 & (5.1) \\
2 & (5.1)\end{array}$ & & $\begin{array}{rr}19 & (41.3) \\
17 & (37.0) \\
6 & (13.0) \\
2 & (4.3) \\
2 & (4.3)\end{array}$ & \\
\hline \multicolumn{5}{|l|}{ Gender } \\
\hline $\begin{array}{l}\text { Female } \\
\text { Male }\end{array}$ & $\begin{array}{l}15(38.5) \\
24(61.5)\end{array}$ & & $\begin{array}{l}15(32.6) \\
31(67.4)\end{array}$ & \\
\hline \multicolumn{5}{|l|}{ Grade } \\
\hline $\begin{array}{l}9 \text { th } \\
10 \text { th } \\
11 \text { th } \\
12 \text { th }\end{array}$ & $\begin{array}{r}14(35.9) \\
12(30.8) \\
8(20.5) \\
5(12.8)\end{array}$ & & $\begin{array}{r}17(37.1) \\
14(30.4) \\
8(17.4) \\
7(15.2)\end{array}$ & \\
\hline
\end{tabular}

(10.6\%), and 8 were Asian American or other ethnicities (9.4\%). Ethnicity of this sample was consistent with the total student population in districts from which participants were drawn, but overrepresented Hispanic students and underrepresented Caucasian students when compared with the population of students with ED and LD nationally (U.S. Department of Education, 2002). Thirty-one students were in ninth grade (36.5\%), 26 were in tenth grade $(30.6 \%), 16$ were in eleventh grade $(18.8 \%)$, and 12 were in twelfth grade $(14.1 \%)$. Students with ED and LD had been absent an average of $24.2(S D=19.4)$ and $10.5(S D=8.8)$ days, respectively, over the past 12-month-period school year.

To be included in this study, students had to (a) be receiving special education services under a primary disability category of either ED or LD, (b) provide parental consent for participation, and (c) provide assent to participate. Districtidentified labels were assigned using definitional criteria articulated in IDEA. Table 1 provides a summary of participant characteristics by disability group.
Teachers and Parents. Students' capacities and opportunities to engage in self-determined behavior also were assessed by the special education teacher and by the mother or father of these 85 students. All teachers were female and the majority was Caucasian (72.7\%). Eighty-one percent of teachers were fully credentialed special educators, with the remainder possessing emergency certification waivers. Demographic information was not collected for parent respondents to increase the likelihood of parent participation and ensure anonymity.

\section{SCHOOLS}

Students attended one of four high schools randomly selected from all high schools in two large; culturally diverse suburban school districts in a western state. Two schools were public high schools and two were alternative high schools for students with learning and/or emotional disorders. Mean student ethnicity across the two districts was $43 \%$ Caucasian, 37\% Hispanic, $8 \%$ African American, and 12\% Asian American and other ethnicities. Student enrollment in the four schools ranged from 84 to $2,516(M=1,180)$. 
Graduation rates at the two public high schools averaged $79.6 \%$ (range, $76.4 \%$ to $82.8 \%$ ) and the percentage of students eligible for free/reduced lunch averaged $49 \%$ (range, $13 \%$ to $75 \%$ ).

\section{AIR SELF-DETERMINATION SCALE}

The AIR Self-Determination Scale (Wolman, Campeau, DuBois, Mithaug, \& Stolarski, 1994) is an assessment instrument designed to measure students' capacity for and opportunity to engage in self-determined behavior. The development of this scale was guided by the theory that prospects for self-determination are influenced both by students' skills, knowledge, and beliefs and by opportunities in the environment (Mithaug, 1993; Wolman et al.). The instrument is comprised of 5 scales that are subsumed under two sections: $\mathrm{Ca}$ pacity and Opportunity.

Capacity to Self-Determine. The Capacity section is designed to assess students' adjustment capability by measuring the extent to which students connect beliefs about what they need, want, and could do with their expectations, choices, actions, and results. The 18 items that comprise the Capacity section are divided into three scales (i.e., Ability, Perceptions, and Knowledge) addressing students' (1) ability to perform specific self-determination behaviors, such as setting goals, making choices, and following-up with actions designed to meet those goals ( $n=6$ items); (2) perceptions of the efficacy of students' self-determined behaviors, including their motivation to set personal goals, degree of optimism about being able to achieve goals, and willingness to take risks ( $n=6$ items); and (3) knowledge about self-determination and the behavior it requires ( $n=6$ items). Each of the six items on each scale corresponds to an item on each of the other two scales. For example, the Knowledge scale item, "Student knows how to set expectations and goals that satisfy own interests and needs," corresponds to the Ability scale item, "Student sets expectations and goals that will satisfy own interests, needs, and wants," and the Perceptions scale item, "Student feels free to set own goals and expectations, even if they are different from the expectations others have for the student." Respondents are asked to rate each questionnaire item on a 5-point Likert-type scale to indicate how frequently the student engages in the behavior, ranging from never (1) to always (5).

Opportunity to Self-Determine. The Opportunity section is designed to evaluate the opportunities students have to engage in self-determined behavior at school and at home. The 12 items comprising the Opportunity section are divided into two parallel scales addressing opportunities for self-determination at school ( $n=6$ items) and at home ( $n=6$ items). Example items include: "Student has opportunities at school/at home to explore, express, and feel good about own needs, interests, and abilities"; "Student has opportunities at school/at home to learn about making choices and plans, to make them, and to feel good about them"; and "Student has opportunities at school/at home to change actions and plans to satisfy own expectations." Items in the Opportunity section are rated on a 5-point Likert-type scale to indicate how frequently the student has opportunities to engage in each behavior, ranging from never (1) to always (5).

Format. The format of the AIR Self-Determination Scale varies slightly for each respondent group (i.e., educators, students, parents). As described previously, the educators version (30 total items) is comprised of three scales to rate student capacity to self-determine (i.e., Knowledge, Ability, Perceptions) and two scales to rate student opportunities to engage in self-determined behavior (i.e., Opportunities At School, Opportunities At Home). Although the student and parent versions each contain both scales in the Opportunity section, the versions differ in the number of scales included in the Capacity section (see Table 2). The students' Capacity section includes only items from the Ability and Perceptions scales, whereas the parents' Capacity section includes only items from the Ability scale. In addition, corresponding items are worded slightly different on each version of the AIR Self-Determination Scale. For example, the item on the Ability scale of the educators' version stating "Student expresses own interests, needs, and abilities" is written "I know what I need, what I like, and what I'm good at" and "My child knows what (s)he needs, likes, and is good at" on the student and parent versions, respectively. Scores for the AIR Self-Determination Scale can be reported several ways, including total raw scores and percentage of 
Self-Determination Ratings by Disability Group and Respondent

\begin{tabular}{|c|c|c|c|c|c|c|}
\hline \multirow[b]{2}{*}{ Scale } & \multicolumn{3}{|c|}{ Students With Emotional Disturbance } & \multicolumn{3}{|c|}{ Students With Learning Disabilities } \\
\hline & $\begin{array}{l}\text { Educator } \\
\mathrm{M}(\mathrm{SD})\end{array}$ & $\begin{array}{l}\text { Student } \\
M(S D)\end{array}$ & $\begin{array}{c}\text { Parent } \\
\text { M (SD) }\end{array}$ & $\begin{array}{l}\text { Educator } \\
M(S D)\end{array}$ & $\begin{array}{l}\text { Student } \\
\mathrm{M}(\mathrm{SD})\end{array}$ & $\begin{array}{l}\text { Parent } \\
M(S D)\end{array}$ \\
\hline \multicolumn{7}{|l|}{ Capacity } \\
\hline Ability & $2.56(0.89)$ & $3.34(1.16)$ & $3.06(1.10)$ & $3.75(1.01)$ & $3.69(0.87)$ & $3.70(0.87)$ \\
\hline Perception & $2.85(1.04)$ & $3.36(1.11)$ & - & $3.71(0.95)$ & $3.70(0.86)$ & - \\
\hline Knowledge & $3.03(1.12)$ & - & - & $4.02(0.90)$ & - & - \\
\hline \multicolumn{7}{|l|}{ Opportunity } \\
\hline At school & $4.74(0.47)$ & $3.14(1.18)$ & $3.58(0.82)$ & $4.68(0.65)$ & $3.73(0.80)$ & $4.05(0.82)$ \\
\hline At home & $3.01(0.96)$ & $3.02(1.21)$ & $3.88(0.94)$ & $3.74(0.88)$ & $3.88(0.80)$ & $4.25(0.77)$ \\
\hline
\end{tabular}

total possible score. For purposes of this study, we calculated average mean scores for items on each scale and section separately: This decision was made to retain reference to the original 5-point scale on which each item was initially rated by respondents.

Reliability and Validity. The AIR SelfDetermination Scale has strong reliability and validity (see Mithaug et al., 2003; Wolman et al., 1994). Initial field-testing of the instrument was conducted with an ethnically diverse sample which included youth living in the same geographic region as adolescents in the present study. Validation using factor analysis indicated the presence of four factors explaining $74 \%$ of the variance of the instrument. Reliability tests indicated strong internal consistency (split-half test $=.95$ ) and adequate test-retest reliability (.74 after 3 months). Using the present sample, reliability analyses using Cronbach's alpha were conducted for both individual scales and each section of the AIR Self-Determination Scale separately for educators, students, and parents. All alphas ranged from .89 to $.99(M=.95)$, indicating strong internal consistency.

\section{PROCEDURES}

Sixty students with ED were randomly selected by school district staff from a roster of all students receiving special education services under the $\mathrm{ED}$ label $(N=78)$ at all four participating high schools. Sixty students with LD who were matched on grade level and gender to the ED sample at each school were randomly selected from among all students receiving special education services under the LD label $(N=109)$ at all four schools. Parental consent and student assent to. participate was obtained from 94 students$75.0 \%$ of students with ED and $81.7 \%$ of students with LD. The AIR Self-Determination Scale was completed by students, their primary special education teacher, and one of their parents. Scales were administered to students by research staff at a time deemed appropriate by the special educator and school-site administrator. Special educators completed the scales independently at a convenient time during the school day. Parent scales were mailed home and completed forms were returned to project staff using a self-addressed stamped envelope or to classroom teachers who then submitted them to research staff. Approximate completion time for the scales ranged from 15 to 25 minutes for special educators and students (estimated completion time for parents was not available). Self-determination scales were not completed by 1 student, 2 educators, and 6 parents. Therefore, data were analyzed only for the 85 students who had AIR SelfDetermination Scales completed by all three respondents, resulting in a final participation rate of $70.8 \%$. All data were collected during the spring semester of the academic school year.

\section{DATA ANALYSIS}

A series of two-way mixed analyses of variance (ANOVAs) were conducted to evaluate the effect 
of disability group (i.e., ED, LD) and respondent (i.e., educator, student, parent) on four of five AIR Self-Determination Scale scales: Ability, Perceptions, Opportunities at School, and Opportunities at Home. Disability group was a between-subjects factor and Respondent was a within-subjects factor. Significant interactions were followed up by tests of simple effects to identify differences in self-determination associated with disability label and respondent. Because the Knowledge scale was completed only by educators, an independent samples $t$ test was performed to compare scores for adolescents with ED and LD. For respondent comparisons, effect sizes (ES) were computed using a pooled standard deviation and the correlation between the two subgroups in the denominator (Lipsey \& Wilson, 2001). For disability group comparisons, effect sizes were computed using the pooled standard deviation only in the denominator. Cohen's (1988) benchmarks for small (.2), medium (.5), and large (.8) effect sizes provide one criterion for interpreting these effect sizes. However, as additional research accrues in this area, effect sizes are best interpreted by making comparisons across related studies. In addition, a Pearson productmoment correlation analysis was performed separately for educators, students, and parents to determine the extent to which mean ratings on the Capacity and Opportunities sections were related.

\section{RESULTS}

Means and standard deviations of study variables are displayed by disability group and respondent in Table 2.

\section{CAPACITY FOR SELF-DETERMINATION}

Ability. Results on the Ability scale were analyzed using a two-way ANOVA with repeated measures on one factor. The Disability (ED, LD) $\mathrm{X}$ Respondent (educator, student, parent) interaction was significant, $F(2,166)=7.43, M S e=$ $0.53, p=.001$ (Greenhouse-Geisser Epsilon = 0.97). An examination of the simple effects identified significant differences in ability ratings between respondents for adolescents with $\mathrm{ED}, F(2$, 76) $=10.95, M S e=0.57, p<.001$, but not for adolescents with LD $(p=.899)$. Post-hoc contrasts showed that educators rated the ability of adolescents with ED to engage in self-determined behavior significantly lower than did students $(p$ $<.001 ; \mathrm{ES}=-.83)$ and parents $(p=.002 ; \mathrm{ES}=$ -.47). An examination of the simple effects for disability group indicated that educators, $F(1,84)$ $=32.94, M S e=0.92, p<.001, \mathrm{ES}=-1.24$, and parents, $F(1,84)=8.95, M S e=0.96, p=.004$, $\mathrm{ES}=-.65$, each rated the ability of adolescents with $\mathrm{ED}$ to engage in self-determined behaviors to be significantly lower than the ability of adolescents with LD. Significant differences in the ratings of students were not found $(p=.124$; ES = $-.35)$.

Perceptions. A $2 \times 2$ ANOVA was conducted to evaluate differences in ratings on the Perceptions scale as a function of disability (ED, LD) and respondent (educator, student). The Disability X Respondent interaction was significant, $F(1$, 83 ) $=7.03, M S e=0.40, p=.010$ (GreenhouseGeisser $=0.96$ ). Tests of the simple effects identified significant differences between respondents for adolescents with $\mathrm{ED}, F(1,38)=9.85, M S e=$ $0.52, p=0.003$, with educators' ratings being significantly lower than students' ratings ( $E S=$ -.44). Tests for simple effects revealed no significant difference across respondents $(p=0.96 ; \mathrm{ES}=$ .01) for adolescents with LD. An examination of the simple effects for disability group indicated the educators rated the perceptions of adolescents with ED regarding self-determined behaviors to be significantly lower than the perceptions of adolescents with $\mathrm{LD}, F(1,84)=16.01, M S e=0.98$, $p<.001, \mathrm{ES}=-.87$. No differences were found among students $(p=.112 ; \mathrm{ES}=-.35)$.

Knowledge. An independent samples $t$ test was conducted to evaluate differences in educators' ratings on the Knowledge scale as a function of disability group. Educators' ratings of the knowledge of adolescents with ED about self-determination were significantly lower than their ratings of the knowledge of adolescents with $\mathrm{LD}$, $t(85)=4.54, p<.001, \mathrm{ES}=-.98$.

\section{OPPORTUNITIES FOR}

SELF-DETERMINATION

At School. The Disability (ED, LD) X Respondent (educator, student, parent) interaction 
was significant, $F(2,166)=4.42, M S e=0.54, p=$ .013 (Greenhouse-Geisser Epsilon = 0.99). An examination of the simple effects identified significant differences between respondents for adolescents with $\mathrm{ED}, F(2,76)=36.64, M S e=$ $0.72, p<0.001$, and for adolescents with LD, $F(2,90)=27.52, M S e=0.39, p<0.001$. Posthoc contrasts showed that educators rated adolescents with ED as having significantly more opportunities to engage in self-determined behavior at school than did students $(p<.001$; ES $=$ 2.07 ) or parents $(p<.001 ; \mathrm{ES}=2.51)$. Moreover, students with ED rated opportunities to self-determine at school lower than did their parents $(p$ $=.038 ; \mathrm{ES}=-.53$ ). Similarly, post-hoc contrasts showed that educators rated adolescents with LD as having significantly more opportunities to engage in self-determined behavior at school than did students $(p<.001 ; \mathrm{ES}=1.57)$ or parents $(p<$ .001 ; ES $=1.15)$. Students with LD rated opportunities to self-determine at school lower than did parents $(p=.007 ; \mathrm{ES}=-.37)$. An examination of the simple effects for disability group indicated the students, $F(1,84)=7.26, M S e=0.99, p=$ $.009, \mathrm{ES}=-.59$, and parents, $F(1,84)=6.83$, $M S e=0.67, p=.011, \mathrm{ES}=-.57$, each rated the opportunities for adolescents with ED to engage in self-determined behaviors at school to be significantly lower than the opportunities for adolescents with LD. Significant differences in the ratings of educators were not found $(p=.689$; ES $=.10$ ).

At Home. The Disability (ED, LD) X Respondent (educator, student, parent) interaction was not significant, $F(2,166)=2.51, M S e=0.54$, $p=.085$ (Greenhouse-Geisser Epsilon $=0.99$ ). Therefore, main effects were examined. The main effect of respondent was significant, $F(2,166)=$ 22.65, $M S e=0.58, p<.001$. Post-hoc contrast analysis of the main effect for respondent indicated that parent ratings $(M=4.08)$ of opportunities for self-determination at home were significantly higher than educator $(M=3.40 ; p<$ $.001)$ and student $(M=3.49 ; p<.001)$ ratings. The main effect of disability group also was significant, $F(1,83)=17.88, M S e=1.53, p<.001$, with adolescents with $\operatorname{ED}(M=3.30)$ being judged overall to have significantly fewer opportunities than adolescents with $L D(M=3.96)$ to engage in self-determined behaviors at home.

\section{CORRELATIONS BETWEEN CAPACITY AND OPPORTUNITY}

Overall, a strong relation was identified between ratings of students' capacity for self-determination and opportunities to engage in self-determined behavior. Specifically, significant positive correlations between measures were found for educators $(r=.65, p<.001)$, parents $(r=.63, p<.001)$, and students $(r=.67, p<.001)$.

\section{DISCUSSION}

Increasing the self-determination of adolescents with disabilities remains an important emphasis of recent legislative, policy, and research initiatives. For adolescents with ED, whose educational, employment, and social outcomes are among the most deleterious of all youth with disabilities, the need for additional understanding of students' skills, knowledge, beliefs, and opportunities that enable them to be self-determined remains pressing. This study extends research on self-determination by providing the first examination of the self-determination skills and opportunities for adolescents with ED. Factors such as disability label and respondents were found to differentially influence ratings of self-determination, suggesting areas for practice and future research.

This study makes several contributions to the literature addressing self-determination among high school students with disabilities. First, despite articulation of the importance attached to ensuring that youth with disabilities are equipped with self-determination skills (Carter \& Lunsford, 2005; Field \& Hoffman, 2002), we found that adolescents with ED in this study were judged to have limited capacity to engage in self-determined behavior. This finding may be indicative of the limited direct efforts made by educators nationally to promote the self-determination of adolescents with disabilities in general and adolescents with ED specifically (Mason, Field, \& Sawilowsky, 2004; Wehmeyer et al., 2000). Future research is needed to examine the role that limited self-determination skills may play in contributing to the disappointing outcomes experienced by substantial numbers of youth with ED. 
Moreover, our findings revealed important differences between the self-determination capacities of adolescents with ED and LD. Both special educators and parents rated the capacity of adolescents with $\mathrm{ED}$ to engage in self-determined behavior significantly lower than that of adolescents with LD. Specifically, special educators rated students with $\mathrm{ED}$ as having less knowledge about self-determination and the behavior it requires, diminished ability to demonstrate self-determined behavior, and less confidence regarding the efficacy of their self-determined behavior. Several factors might account for these differences, including the social and behavioral deficits characteristically exhibited by adolescents with ED (Cullinan \& Sabornie, 2004; Nelson, Babyak, Gonzalez, \& Benner, 2003) and the pervasive impact these deficits have on related skill development and support needs. However, additional research is needed to determine the extent to which differences in ratings are influenced by extraneous factors (e.g., respondent biases) and whether ratings correspond with direct observations of student behavior.

\section{Future research is needed to examine}

the role that limited self-determination skills may play in contributing to the disappointing outcomes experienced by substantial numbers of youth with $E D$.

Second, this study also documented important differences in the self-determination skill appraisals of various stakeholders. Most apparent was the finding that evaluations of students with ED, but not students with LD, diverged from those of their teachers. Specifically, teachers' ratings of students' capacity for self-determination were significantly lower than students' selfappraisals. Such discrepancies are not unusual among youth with disabilities in other domains (e.g., Stone \& May, 2002) and corroborate prior research indicating that adolescents with $\mathrm{ED}$ may encounter difficulty accurately evaluating their own behavioral performance against expected standards or behavioral norms (e.g., Carter \& Wehby, 2003; Gresham, Lane, MacMillan,
Bocian, \& Ward, 2000). Although individualized instructional decisions remain a hallmark of special education services, our descriptive findings call attention to the prospect that adolescents with ED may benefit from additional curricular attention on and explicit instruction in self-determination components such as goal setting, choice making, problem-solving, and self-evaluation. Moreover, although the self-ratings of students with ED differed significantly from teacher ratings, this is not an indicator that students rated themselves highly with regard to their own selfdetermination. In fact, students' moderate selfratings indicate that they may recognize their own limitations in this area, though to a lesser extent than teachers, and thus may be receptive to receiving focused instruction in this area. Future research should explore this possibility using interview or other in-depth methodology.

Third, we documented substantial disparities in the evaluations of opportunities for self-determination available to students with ED and LD. These disparities in opportunities may be a primary factor contributing to the differences in selfdetermination attributed to youth with ED and LD. Adolescents with ED identified few opportunities - both at school and at home- to engage in self-determined behavior. For adolescents with ED who often have difficulty recognizing the value of high school and are at heightened risk of dropping out (Scanlon \& Mellard, 2002), a secondary curriculum that embeds frequent opportunities and supports for students to exercise and develop their self-determination skills may comprise one component of a multifaceted approach toward improving students' perceptions regarding the relevance and efficacy of school and their willingness to remain enrolled (e.g., Benz, Lindstrom, \& Yovanoff, 2000; Kortering, Braziel, \& Tompkins, 2002). Such a focus is particularly important given the high rates of absenteeism of youth with ED in this study.

In addition, differences in evaluations of selfdetermination opportunities were clearly apparent across special educators, parents, and students. Discrepancies between educators and parents regarding opportunities for self-determination at school and at home are particularly striking, with educators asserting that few self-determination opportunities exist for students at home and 
parents countering that diminished opportunities exist at school. These differences may arise because educators and teachers do not have direct daily involvement in home and school settings, respectively. Thus, adults' knowledge about opportunities available within other settings may depend primarily on the information that is communicated by students-a group that possesses diminished evaluations of opportunities in both settings. These findings also suggest that there may be little communication between teachers and parents regarding what each are doing to promote self-determination in their respective settings. Discussions between parents and teachers would contribute to a shared understanding of self-determined behavior, promote agreement regarding what constitutes a meaningful opportunity for self-determination, and ensure that there is consistency in opportunities for selfdetermination across settings. Our findings corroborate those of Zhang et al. (2002), who found significant differences between parent and teacher ratings of self-determination opportunities for youth with high incidence disabilities, but diverge from Zhang et al. (2005), where similar differences were not identified. These differences may be attributed to our use of different measures and sampling procedures.

Fourth, findings from the correlational analysis provide insight into the association between opportunities and capacities for self-determination that has not been documented in prior research studies. Ratings of capacity for and opportunity to engage in self-determined behavior were strongly correlated among all respondents. Although an understanding of causal influences is not accessible with this analysis, it is clear that both focused skill development and provision of opportunities must be combined into intervention efforts. Neither providing frequent opportunities apart from instruction in self-determination skills nor promoting skill development when opportunities do not exist are effective strategies for fostering self-determined adolescents. Additional research is needed to examine how these two areas could most optimally be addressed within the secondary curriculum.
IMPLICATIONS FOR FUTURE RESEARCH AND PRACTICE

Findings from this study have important implications for the provision of secondary educational programming to adolescents with ED. Our findings suggest that additional attention needs to be devoted to promoting the self-determination of students with ED. Although these data, coupled with the pejorative outcomes experienced by substantial numbers of young adults with $\mathrm{ED}$, document the considerable need for intervention, they also prompt important questions and concerns regarding where, how, and when to intervene to increase student self-determination.

First, self-determination assessment instruments such as the one used in this study (for other examples, see Wehmeyer, 2001), may offer effective and efficient tools for identifying areas of student strength and need, informing the development of individualized educational goals, and tracking skill development and progress over time. Moreover, periodic assessments by students, parents, and multiple educators also can serve as "self-checks" to ensure that self-determination opportunities are indeed provided to students throughout the curriculum and across school, home, and community settings.

Second, a primary hurdle to addressing adolescents' skill development related to self-determination is the near absence of empirically validated interventions for increasing the self-determined behavior of adolescents with ED (e.g., Algozzine et al., 2001; Test et al., 2004). Lacking validated interventions, it is not surprising that teachers report feeling ill-equipped to address self-determination and uncertain about the effectiveness or appropriateness of strategies to facilitate self-determination (e.g., Thoma, Nathanson, Baker, \& Tamura, 2002; Wehmeyer et al., 2000). Researchers must increase efforts toward designing and evaluating interventions for students with ED (e.g., Houchins, 2002; Martin et al., 2003; Snyder, 2002; Snyder \& Shapiro, 1997). Systematic replication of interventions found to be effective with youth with other disability labels would contribute greatly to determining intervention effectiveness with high school students with ED. Moreover, educators can contribute to further understanding of this area by taking steps to more 
systematically examine the impact of their own instructional practices on students' outcomes in the area of self-determination.

Third, as effective interventions are identified, the question remains concerning when and where within the secondary curriculum that selfdetermination should be addressed. Answers to this question are further complicated by the multitude of other instructional priorities and standards-based reform issues already competing for the attention of secondary educators. Moreover, in light of substantial academic needs and, in particular, behavioral challenges characteristic of adolescents with ED, educators may not view promoting self-determination as a high priority. Several tentative suggestions have been offered in the literature to counter these barriers, including starting efforts to address self-determination in earlier grades, prior to students entering high school; infusing self-determination instruction throughout the school day, rather than treating it exclusively as an add-on to the curriculum; and making self-determination instruction an integral part of the general curriculum for all students, not just students with disabilities (e.g., Eisenman \& Chamberlin, 2001; Mason et al., 2004; Wehmeyer, Field, Doren, Jones, \& Mason, 2004).

\section{LIMITATIONS}

Several limitations to this study suggest additional areas for future research. First, self-determination is a complex construct that can and has been operationalized multiple ways (e.g., Field \& Hoffman, 1996; Halpern et al., 1997; Martin \& Marshall, 1996; Wehmeyer \& Kelchner, 1995). In this study, we utilized the AIR Self-Determination Scale as the only measure of self-determination. Future research should incorporate additional measures to assess different components that comprise the self-determination construct. Moreover, our findings of discrepancies across educator, student, and parent responses argue for the importance of including direct observation measures in future investigations of self-determination. Second, although we investigated ratings of students' selfdetermination capacities and opportunities from multiple perspectives, it would be valuable to query general education teachers regarding the importance of and opportunities for promoting self-determination (Eisenman \& Chamberlin, 2001), particularly as increasing numbers of youth with ED are spending time within the general education classroom. Furthermore, because most adolescents with ED will encounter a constellation of service and support providers, it is critical that these providers' views of self-determination also be evaluated (Cook \& Jonikas, 2002; Izzo \& Lamb, 2003). Students benefit little when self-determined behavior is promoted in one setting, but stifled in other contexts.

Third, data were drawn from a single geographic region with only two school districts. However, most of our sample was comprised of adolescents from ethnic minority groups, a population of youth for whom research on transitionrelated issues is particularly limited (Geenen; Powers, Lopez-Vasquez, \& Bersani, 2003). Future research should replicate these findings in additional regions of the country and include crosscultural comparisons with a broader participant sample to enhance generalizability of findings (Trainor, 2002). Fourth, self-determination is

Students benefit little when self-determined
behavior is promoted in one setting, but
stifled in other contexts.

often considered in isolation of other skill areas, as in the present study. There remains a need for understanding the relation between self-determination and other skill areas. Perhaps self-determination outcomes correspond more closely with social and behavioral deficits than with disability labels. Future research should examine the association between self-determination and acquisition of other skills, including academic, social, behavioral, and vocational domains. Fifth, we relied on school district-provided labels when categorizing students as ED or LD. Future research should include verification of the extent to which these labels are appropriately applied at the high school level (Gersten et al., 2005).

\section{CONCLUSION}

Considerable efforts have been directed toward understanding and increasing the self-determina- 
tion of adolescents with disabilities. Our findings suggest that, for adolescents with $\mathrm{ED}$, there remains much still to accomplish. This study documented the diminished capacities and opportunities for self-determination among adolescents with ED. Additional research is needed to investigate other variables that may influence selfdetermination outcomes for youth with $\mathrm{ED}$, including age, gender, ethnicity, socioeconomic status, and school placement patterns. Most important, research examining the long-term impact of addressing self-determination on the postschool lives of adolescents remains sorely needed.

\section{REFERENCES}

Agran, M., Snow, K., \& Swaner, J. (1999). Teacher perceptions of self-determination: Benefits, characteristics, and strategies. Education and Training in Mental Retardation and Developmental Disabilities, 34, 293-301.

Algozzine, B., Browder, D., Karvonen, M., Test, D. W., \& Wood, W. M. (2001). Effects of interventions to promote self-determination for individuals with disabilities. Review of Educational Research, 71, 219-277.

Andèrson, J. A., Kutash, K., \& Duchnowski, A. J. (2001). A comparison of the academic progress of students with E/BD and students with LD. Journal of Emótional and Behavioral Disorders, 9, 106-115.

Beriz, M. R., Lindstrom, L., \& Yovanoff, P. (2000). Improving graduation and employment outcomes of students with disabilities: Predictive factors and student perspectives. Exceptional Children, 66, 509-529.

Carlson, E., Brauen, M., Klein, S., Schroll, K., \& Westat, S. W. (2002). Study of personnel needs in special education: Key findings. Washington, DC: U.S. Department of Education.

Carter, E. W., \& Lunsford, L. B. (2005). Meaningful work: Preparing transition-age youth with emotional and behavioral disorders for employment. Preventing School Failure, 49(2), 63-69.

Carter, E. W., \& Wehby, J. H. (2003). Job performance of transition-age youth with emotional and behavioral disorders. Exceptional Children, 69, 449-465.

Cohen, J. (1988). Statistical power analysis for the behavioral sciences (2nd ed.). Hillside, NJ: Lawrence Erlbaum Associates.

Cook, J. A., \& Jonikas, J. A. (2002). Self-determination among mental health consumers/survivors. Journal of Disability Policy Studies, 13, 87-95.
Council for Exceptional Children (2003). What every special educator must know: Ethics, standards, and guidelines for special educators (5th ed). Arlington, VA: Author.

Cullinan, D., \& Sabornie, E. J. (2004). Characteristics of emorional disturbance in middle and high school students. Journal of Emotional and Behavioral Disorders, 12, 157-167.

Eisenman, L. T., \& Chamberlin, M. (2001). Implementing self-determination activities: Lessons from schools. Remedial and Special Education, 22, 138-147.

Field, S., \& Hoffman, A. (1996). Steps to self-determination: $A$ curriculum to help adolescents learn to achieve their goals. Austin, TX: Pro-Ed.

Field, S., \& Hoffman, A. (2002). Preparing youth to exercise self-determination: Quality indicators of school environments that promote the acquisition of knowledge, skills, and beliefs related to self-determination. Journal of Disability Policy Studies, 13, 113-118.

Field, S., Sarver, M. D., \& Shaw, S. F. (2003). Self-determination: A key to success in postsecondary education for students with learning disabilities. Remedial and Special Education, 24, 339-349.

Field, S. S., Martin, J. E., Miller, R. J., Ward, M., \& Wehmeyer, M. L. (1998). Self-determination for persons with disabilities: A position statement of the Division on Career Development and Transition. Career Development for Exceptional Individuals, 21, 113-128.

Geenen, S., Powers, L., Lopez-Vasquez, A., \& Bersani, H. (2003). Understanding and promoting the transition of minority adolescents. Career Development for Exceptional Individuals, 26, 27-46.

Gersten, R., Fuchs, L. S., Compton, D., Coyne, M., Greenwood, C., \& Innocenti, M. S. (2005). Quality indicators for group experimental and quasi-experimental research in special education. Exceptional Children, 71, 149-164.

Gresham, F. M., Lane, K. L., MacMillan, D. L., Bocian, K. M., \& Ward, S. L. (2000). Effects of positive and negative illusory biases: Comparisons across social and academic self-concept domains. Journal of School Psychology, 38, 151-175.

Grigal, M., Neubert, D. A., Moon, M. S., \& Graham, S. (2003). Self-determination for students with disabilities: Views of parents and teachers. Exceptional Children, 70, 97-112.

Halpern, A. S., Herr, C. M., Wolf, N. K., Doren, B., Johnson, M. D., \& Lawson, J. D. (1997). Next S.T.E.P.: Student transition of educational planning. Austin, TX: PRO-ED. 
Houchins, D. E. (2002). Self-determination knowledge instruction and incarcerated students. Emotional and Behavioural Difficulties, 7, 132-151.

Individuals with Disabilities Education Improvement Act of 2004. Pub. L. No. 108-446, 118 Stat. 2647 (2004).

Izzo, M. V., \& Lamb, P. (2003). Developing self-determination through career development activities: Implications for vocational rehabilitation counselors. Journal of Vocational Rehabilitation, 19, 71-78,

Karvonen, M., Test, D. W., Wood, W. M., Browder, D., \& Algozzine, B. (2004). Putting self-determination into practice. Exceptional Children, 71, 23-41.

Kortering, L. J., Braziel, P. M., \& Tompkins, J. R. (2002). The challenge of school completion among youths with behavioral disorders: Another side of the story. Behavioral Disorders, 27, 142-154.

Lane, K. L., Carter, E. W., Pierson, M., \& Glaeser, B. (in press). Academic, social, and behavioral characteristics of high school students with emotional disturbance and learning disabilities. Journal of Emotional and Behavioral Disorders.

Lipsey, M. W., \& Wilson, D. B. (2001). Practical metaanalysis. Thousand Oaks, CA: Sage.

Malian, I., \& Nevin, A. (2002). A review of self-determination literature: Implications for practitioners. $R e-$ medial and Special Education, 23, 68-74.

Martin, J. E., \& Marshall, L. H. (1996). ChoiceMaker Self-determination Transition Assessment. Longmont, CỌ: Sopris West.

Martin, J. E., Mithaug, D. E., Cox, P., Peterson, L. Y., Van Dycke, J. L., \& Cash, M. E. (2003). Increasing self-determination: Teaching students to plan, work, evaluate, and adjust. Exceptional Children, 69, $431-447$.

Mason, C., Field, S., \& Sawilowsky, S. (2004). Implementation of self-determination activities and student participation in IEPs. Exceptional Children, 70, $441-451$.

Mithaug, D. E. (1993). Self-regulation theory: How optimal adjustment maximizes gain. Westport, CT: Praeger.

Mithaug, D. E., Mithaug, D., Agran, M., Martin, J., \& Wehmeyer, M. L., (Eds.). (2003), Self-determined learning theory: Construction, verification, and evaluation. Mahwah, NJ: Lawrence Lawrence Erlbaum Associates.

National Council on Disability. (2004). Improving educational outcomes for students with disabilities. Washington, DC: Author.

Nelson, N. J., Babyak, A., Gonzalez, J., \& Benner, G. J. (2003). An investigation of the types of problem be- haviors exhibited by $\mathrm{K}-12$ students with emotional or behavioral disorders in public school settings. Behavioral Disorders, 28, 348-359.

President's Commission on Excellence in Special Education. (2002). A new era: Revitalizing special education for children and their families. Washington, DC: U.S. Department of Education, Office of Special Education and Rehabilitative Services.

Rehabilitation Act Amendments of 1992, Pub. L. No. 102-569, 29 U.S.C. $\$ 701$ et seq. (1992).

Rehabilitation Act Amendments of 1998, Pub. L. No. 105-220, 29 U.S.C. $\$ 701$ et seq. (1998).

Ryan, R. M., \& Deci, E. L. (2000). Self-determination theory and the facilitation of intrinsic motivation, social development, and well-being. American Psychologist, 55, 68-78.

Sabornie, E. J., \& deBettencourt, L. U. (2004). Teaching students with mild and high-incidence disabilities at the secondary level (2nd ed.). Upper Saddle River, NJ: Prentice Hall.

Scanlon, D., \& Mellard, D. F. (2002). Academic and participation profiles of school-age dropours with and without disabilities. Exceptional Children, 68, 239-258.

Snyder, E. P. (2002). Teaching studenț with combined behavioral disorders and mental retardation to lead their own IEP meetings. Behavioral Disorders, 27, 340-357.

Snyder, E. P., \& Shapiro, E. S. (1997). Teaching ștudents with emotional/behavioral disorders the skills to participate in the development of their own IEPs. Behavioral Disorders, 22, 246-249.

Sowers, J., \& Powers, L. (1995). Enhancing the participation and independence of students with severe physical and multiple disabilities in performing community activities. Mental Retardation, 33, 209-220.

Stone, C. A., \& May, A. L. (2002). The accuracy of academic self-evaluations in adolescents with learning disabilities. Journal of Learning Disabilities, 35 , 370-383.

Test, D. W., Mason, C., Hughes, C., Konrạad, M., Neale, M., \& Wood, W. M. (2004). Student involvement in individualized education program meetings. Exceptional Children, 70, 391-412.

Thoma, C. A., Nathanson, R., Baker, S. R., \& Tamura, R. (2002). Self-determination: What do special educators know and where do they learn it? Remedial and Special Education, 23, 242-247.

Trainor, A. (2002). Self-determination for students with learning disabilities: Is it a universal value? Qualitative Studies in Education, 16, 711-725. 
U.S. Department of Education. (2002). Twenty-fourth annual report to Congress on the implementation of the Individuals with Disabilities Education Act. Washington, DC: Author.

Wagner, M., Cameto, R., \& Newman, L. (2003). Youth with disabilities: A changing population: $A$ report of findings from the National Longitudinal Transition Study (NLTS) and the National Longitudinal Transition Study2 (NLTS2). Menlo Park, CA: SRI International.

Wehmeyer, M. L. (2001). Assessment in self-determination: Guiding instruction and transition planning. Assessment for Effective Intervention, 26(4), 41-49.

Wehmeyer, M. L., Agran, M., \& Hughes, C. (2000). A national survey of teachers' promotion of self-determination and student-directed learning. Journal of Special Education, 34, 58-68.

Wehmeyer, M. L., Field, S., Doren, B., Jones, B., \& Mason, C. (2004). Self-determination and student involvement in standards-based reform. Exceptional Children, 70, 413-425.

Wehmeyer, M. L., \& Kelchner, K. (1995). The Arc's self-determination scale. Arlington, TX: The Arc National Headquarters.

Wehmeyer, M. L., \& Palmer, S. B. (2003). Adult outcomes for students with cognitive disabilities three years after high school: The impact of self-determination. Education and Training in Developmental Disabilities, 38, 131-144.

Wehmeyer, M. L., \& Schwartz, M. (1997). Self-determination and positive adult outcomes: A follow-up study of youth with mental retardation or learning disabilities. Exceptional Children, 63, 245-255.

Wolman, J. M., Campeau, P. L., DuBois, P. A., Mithaug, D. E., \& Stolarski, V. S. (1994). AIR self-determination scale and user guide. Palo Alto, CA: American Institutes for Research.

Wood, S. J., \& Cronin, M. E. (1999). Students with emotional/behavioral disorders and transition planning: What the follow-up studies tell us. Psychology in the Schools, 36, 327-345.

Zhang, D., Katsiyannis, A., \& Zhang, J. (2002). Teacher and parent practice on fostering self-determination of high school students with mild disabilities. Career Development for Exceptional Individuals, 25, 157-169.

Zhang, D., Wehmeyer, M. L., \& Chen, L. (2005). Parent and teacher engagement in fostering the self- determination of students with disabilities: A comparison between the United States and the Republic of China. Remedial and Special Education, 26, 55-64.

\section{ABOUT THE AUTHORS}

ERIK W. CARTER (CEC WI Federation), Assistant Professor, Department of Rehabilitation Psychology and Special Education, University of Wisconsin-Madison. KATHLEEN L. LANe (CEC TN Federation), Assistant Professor, Department of Special Education, Peabody College of Vanderbilt University, Nashville, Tennessee. MELINdA R. PIERSON (CEC CA Federation), Professor, Department of Special Education, California State University at Fullerton. BARBARA glaeser (CEC CA Federation), Associate Professor, Department of Special Education, California State University at Fullerton.

Address all correspondence to Erik W. Carter, Department of Rehabilitation Psychology and Special Education, University of Wisconsin-Madison, 432 North Murray Street, Madison, WI, 53706 (e-mail: ewcarter@education.wisc.edu).

Manuscript received April, 2005; accepted July, 2005.

\section{INDEX OF ADVERTISERS}

Charles C Thomas Publishers, Ltd., cover 3

Council for Exceptional Children, cover 2, $257,298,332,361$, cover 4

Long Island University, 362

National University, 280

Regent University, 298 
Copyright of Exceptional Children is the property of Council for Exceptional Children and its content may not be copied or emailed to multiple sites or posted to a listserv without the copyright holder's express written permission. However, users may print, download, or email articles for individual use. 